\title{
Triploid frequency of sexual hybridization and pollen and ovary development in mandarins
}

\author{
Shirley Nascimento Costa ${ }^{1,2}$. Priscila Andressa Cortez ${ }^{1}$ Lucas Aragão da Hora Almeida ${ }^{1}$ \\ Fabiano Machado Martins ${ }^{3} \cdot$ Walter dos Santos Soares Filho ${ }^{4}$. Mauricio Antônio Coelho Filho ${ }^{4}$. \\ Abelmon da Silva Gesteira ${ }^{1,4}$ (1)
}

Received: 5 September 2018 / Accepted: 4 January 2019

(c) Botanical Society of Sao Paulo 2019

\begin{abstract}
This work aimed to ascertain the triploid frequency of sexual hybridization and the pollen and ovary development in Citrus. The 'Fortune' mandarin (Citrus clementina Hort. ex Tan. $\times$ C. tangerina Hort. ex Tan.) accession was selected as female parent for this study based on its reproductive characteristics, mainly the monoembryony and self-incompatibility. The male parents used were the 'Cravo' (C. reticulata, Blanco) and 'Dancy' (C. reticulata) mandarins. The pollinations were always manually performed in the morning, and the pollinated flowers were identified for control. During the flowering period, flower samples at different stages of development of the 'Fortune' variety were collected for histological analysis. Microspore development occurred regularly in the 4-5 mm (length) phase of the floral buds, and a bicellular microgametophyte was formed in the floral buds with 5-6 mm in length. The formation of the female gametophyte occurred later, in flower buds with approximately $10 \mathrm{~mm}$ in length. The hybridizations resulted in 19 triploid plants: five when the 'Cravo' mandarin was used as the male parent and 14 when 'Dancy' mandarin was used as the male parent, evidencing the importance of the male genitor also in this process.
\end{abstract}

Keywords Clementine $\times C$. tangerine $\cdot$ Flower $\cdot$ Unreduced gametes

\section{Introduction}

Citrus (Rutaceae) is a genus that originated in Southeast Asia (Soost and Cameron 1975) that includes species with great importance for Brazilian agribusiness. Citrus plants are usually diploid and have 18 chromosomes, but triploids and tetraploids also occur. Brazil is the world leader in export of citrus juices, accounting for approximately $40 \%$ of global trade, generating revenue of around US\$ 2 billion in 2014 (FAO 2017). This revenue would be even higher if

Abelmon da Silva Gesteira

abelmon.gesteira@embrapa.br

1 Universidade Estadual de Santa Cruz, Jorge Amado, Km 16, Ilhéus, BA, Brazil

2 Faculdade Santo Antônio, Rua Conselheiro Junqueira, Alagoinhas, BA, Brazil

3 Universidade Federal do Recôncavo da Bahia, Rua Rui Barbosa, Cruz das Almas, Brazil

4 Embrapa Mandioca e Fruticultura, Rua da Embrapa, Cruz das Almas, BA, Brazil
Brazil invested in growing table fruits with higher value, as is common in countries such as Spain and Egypt, which mainly grow seedless triploid varieties that are more valuable. Therefore, it is necessary to stimulate the development of the fresh fruit segment in Brazil by investing in the development of new triploid varieties with high-quality characteristics that increase the market value, such as those with no seeds, easily removable peels and highly soluble solids content (Ollitrault et al. 2008).

The use of triploid hybrids is an important breeding strategy to develop new Citrus varieties (Ollitrault et al. 2008), since most existing commercial varieties are diploids, with the exception of some natural polyploids (Guerra 2009). Recently, new triploid genotypes have been obtained by sexual hybridizations (Otto 2007; Aleza et al. 2009), but some environmental factors such as cold weather, injuries, nutritional and water deficit are directly related to the formation of unreduced gametes and flowering (Iglesias et al. 2007; Aleza et al. 2010; Pécrix et al. 2011; Storme and Geelen 2013). 
Flowering parameters directly influence fruit characteristics such as size, juice quality, texture and color (Abouzari and Mahdi 2016). However, despite the economic importance, there is still a scarcity of anatomical studies regarding the reproductive structures of most Citrus varieties to provide useful information about selection of economically important varieties in breeding programs.

The structural analysis of the flowers in several developmental stages can indicate abnormalities in the process that lead to the formation of fruits and viable seeds, besides understanding which cell types undergo changes that culminate in the meiotic alterations that are responsible to seed abortion. Considering that both sporogenesis and gametogenesis occur inside the flowers, the structural characterization of these processes in the varieties is fundamental.

To our knowledge, there are no studies on the ploidy level of 'Fortune' mandarins submitted to Brazilian cultivation conditions. This study investigated the triploid frequency of sexual hybridization and the anatomical aspects of pollen and ovary development in citrus plants. The characterization of floral anatomy is important for genetic improvement programs, since obtaining varieties depends on knowledge of the development of these structures, such as the formation of gametophytes and sporophytes. In addition, crosses were performed to identify the contribution of the male genitor to formation of triploid hybrids.

\section{Materials and methods}

The 'Fortune' mandarin accession was selected for this study based on its reproductive characteristics, mainly monoembryony, self-incompatibility and high frequency of producing triploid hybrids when used as the female parent in crosses between diploid parents (Hodgson 1967; Aleza et al. 2010). The male parents used in this study were 'Cravo' and 'Dancy' mandarins. All the steps of this study were conducted between 2014 November and 2016 March.

The accessions of 'Fortune' and 'Cravo' mandarin, from the Citrus Active Germplasm Bank of the Embrapa Cassava and Fruits research unit, located in Cruz das Almas, Bahia, Brazil, were grafted on the hybrid 059 \{common 'Sunki' mandarin [C. sunki (Hayata) hort. ex Tanaka] $\} \times\{$ 'Rangpur' lime $(C$. limonia Osbeck $) \times$ trifoliate orange $[$ Poncirus trifoliata (L.) Raf.]\}, obtained from the Citrus Breeding Program of Embrapa Cassava and Fruits, and then transferred to $45 \mathrm{~L}$ pots containing a mixture of washed sand, soil and Rendmax Citrus, a commercial pine bark substrate $(2: 1: 2)$.

The experiment was conducted in a completely randomized design, with two treatments and 15 repetitions. In both treatments, the 'Fortune' mandarin was used as female genitor, while the male parent was the 'Cravo' mandarin in treatment 1 and the 'Dancy' mandarin in treatment 2 (Table 1). The effects of the treatments on the studied variables were evaluated through analysis of variance, and the means were compared by the Tukey test $(P<0.05)$, using the statistical program Genes (Table 1) (Cruz 2006).

Climatic variables including air temperature, relative humidity and radiation were monitored using a weather station installed at the experimental site. The matric potential was estimated at the Soil Physics Laboratory of Embrapa Cassava and Fruits in Cruz das Almas, based on both the Van Genuchten (1980) model and the humidity values.

During the experiment, all plants were kept under irrigation. The pots were covered with aluminum foil to prevent evaporation. The soil water content was measured using a time-domain reflectometry probe constructed by hand containing three stainless steel rods with diameter of 0.003 and length of $0.15 \mathrm{~m}$ long, spaced $0.022 \mathrm{~m}$ apart, insulated with polyester resin and fitted with RG58 coaxial cables (50 ohms) with length of $0.75 \mathrm{~m}$. The plants were irrigated every 2 days based on the data obtained from the time-domain reflectometry readings, replacing only the amount of water required to stabilize the treatment.

For the hybridization and ploidy analysis, the pollinations were always manually performed in the morning and the pollinated flowers were identified for control. About 30 flowers were pollinated per plant. Some pollinated flowers aborted and others were cut off due to the accumulation of fruit on the branch. Routine treatments were carried out throughout

Table 1 Distribution and effect of each treatment on number of fruits, number of seeds, number of small seeds, number of normal seeds and triploids obtained by normal seeds and small seeds

\begin{tabular}{llllllll}
\hline Male parents & Female parents & Number of fruits & Total seeds & $\begin{array}{l}\text { Number of small } \\
\text { seeds }\end{array}$ & $\begin{array}{l}\text { Number of trip- } \\
\text { loids from small } \\
\text { seeds }\end{array}$ & $\begin{array}{l}\text { Number of normal } \\
\text { seeds }\end{array}$ & $\begin{array}{l}\text { Triploids } \\
\text { from normal } \\
\text { seeds }\end{array}$ \\
\hline Cravo & Fortune & $5.3 \mathrm{a}^{*}(48)$ & $98.88 \mathrm{~b}^{*}(890)$ & $1.22 \mathrm{~b}^{*}(11)$ & $0.22 \mathrm{a}^{*}(2)$ & $97.66 \mathrm{~b}^{*}(879)$ & $0.36 \mathrm{~b}^{*}(3)$ \\
Dancy & Fortune & $4.8 \mathrm{a}^{*}(44)$ & $117.44 \mathrm{a}^{*}(1057)$ & $2.66 \mathrm{a}^{*}(24)$ & $0.00 \mathrm{a}^{*}(0)$ & $114.77 \mathrm{a}^{*}(1033)$ & $0.99 \mathrm{a}^{*}(14)$ \\
\hline
\end{tabular}

*Means followed by the same letters in the rows do not differ statistically from each other by the Tukey test $5 \%$ probability. Numbers followed by letters outside the parentheses correspond to the means of each treatment

Values within the parentheses correspond to the absolute values in number of fruits, number of seeds, number of small seeds, number of normal seeds and triploids obtained by normal seeds and small seeds 
the period for pest control. To prevent self-pollination, the plants used as female parents were emasculated using tweezers.

Five months after the manual pollination, the ripe fruits were harvested and their seeds were extracted. The seeds were placed in a calcareous solution (calcium hydroxide and magnesium hydroxide), washed in running water to remove the mucilage and stored in paper bags for $24 \mathrm{~h}$ at room temperature until they were dry. The seeds were counted according to their genotype and measured using a caliper for the following classification: normal, small (when having $1 / 6$ to $1 / 3$ of the normal size) and inviable (when withered). The normal seeds were sown directly in seedbeds containing pine bark substrate. Only small seeds were used for the in vitro germination analyses.

For identification of triploid hybrids, after acclimatization and germination of the seedlings, leaves were collected to confirm the level of ploidy with the aid of a flow cytometer (Attune ${ }^{\circledR}$ Acoustic Focusing-Life Technologies). The protocol of Dolezel et al. (2007), with modifications, was used. Tests with the Crotalaria breviflora DC. species were performed comparing it with a citrus standard to define the DNA content. The analysis was performed using triplicate samples of fragments of citrus leaves $(2 \mathrm{C}=0.70 \mathrm{pg}$ DNA), comparing them with the content of $C$. breviflora $(2 \mathrm{C}=2.02 \mathrm{pg}$ DNA). The samples were macerated in Petri dishes on ice in the presence of $1 \mathrm{ml}$ of core isolation buffer (LB01, Galbraith's buffer, Tris.MgCl2 buffer) followed by addition of $0.20 \mu \mathrm{l}$ of propidium iodide to stain the DNA.

The seed surface was sterilized with a solution of sodium hypochlorite containing $0.5 \%$ active chlorine, for $10 \mathrm{~min}$. The embryos were extracted from the seeds under a stereomicroscope (SMZ7.5, Feldmann) and cultured in a sterile Petri dish containing woody plant medium (Lloyd and McCown 1981), at $\mathrm{pH}$ 5.8. After germination, the seedlings were transferred to test tubes containing the same culture medium and kept in a growth room in the presence of white light with an intensity of $36 \mu \mathrm{mol} \mathrm{m}^{-2} \mathrm{~s}^{-1}$ and photoperiod of $16 \mathrm{~h}$ at temperature of $25^{\circ} \mathrm{C}$.

For the structural analyses, flower buds at various developmental stages of the 'Fortune' mandarin variety were collected and selected based on their sizes, from 1 to $10 \mathrm{~mm}$ in length. The samples were fixed using a solution containing formaldehyde, 50\% ethanol and glacial acetic acid (FAA, 1:18:1) for $24 \mathrm{~h}$ at room temperature (Johansen 1940). Several cycles of vacuum were applied to the samples during the fixation process to ensure better preservation of cell components.

Samples were dehydrated in a crescent series of tertiary butyl alcohols and embedded in paraffin (Johansen 1940). Longitudinal and transverse serial sections with 5-14 $\mu \mathrm{m}$ thick were obtained using a rotating microtome (2245, Leica). The sections were placed on glass slides and stained with 3\% ethanolic safranin (CI 50240) and 2\% aqueous Astra blue (Gerlach 1969). The observations and photomicrographs were carried out using a light microscope (BX51, Olympus) with an attached digital camera (E330, Olympus).

\section{Results}

Eight hundred and ninety seeds from 48 fruits were obtained from the pollination between 'Cravo and 'Fortune' mandarins. All the seeds obtained from 'Fortune' mandarin were monoembryonic. In the developed seeds, two groups were identified: 11 small seeds and 879 normal seeds (Table 1). Normal seeds were germinated in a greenhouse, and of these, 876 produced diploid plantlets and three generated triploids. Embryos were rescued from the 11 small seeds and cultured in vitro. Eleven plants were obtained, of which nine were diploid and two triploid (Table 1).

From the reciprocal crosses between the 'Fortune' and 'Dancy' mandarins, 1057 seeds were obtained from 44 fruits (Table 1), of which 24 were classified as small and 1033 as normal (Table 1). No triploid plants were obtained from the small seeds, and 14 triploid hybrids were recovered from the normal seeds (Table 1). The average area of small seeds was $12 \mathrm{~mm}^{2}$ when a 'Fortune' mandarin was hybridized with 'Cravo' and $12.3 \mathrm{~mm}^{2}$ when 'Fortune' mandarin was hybridized with 'Dancy'. The average number of seeds per fruit varied between 18.5 from 'Cravo' mandarin and 24.0 from 'Dancy' mandarin.

The efficiency of obtaining triploid hybrids was calculated based on the number of triploid hybrids per seed. Triploid hybrids were obtained most efficiently when 'Fortune' mandarin was crossed with 'Dancy' mandarin, with an average of 0.013 triploid hybrids per seed. In the second treatment, when 'Fortune' mandarin was crossed with 'Cravo' mandarin, the efficiency was 0.006 triploid hybrids per seed.

The highest percentage of triploids was identified when the 'Fortune' mandarin was crossed with 'Dancy' mandarin. The production of triploid embryos was significantly affected by the male parent (Table 1). Flow cytometry was used to identify these triploids.

This is the first structural description of the flowers, sporogenesis and gametogenesis of the 'Fortune' mandarin. The 'Fortune' mandarin flowers are pentamerous, monoclines and actinomorphic, with calyx, corolla, androecium and gynoecium (Fig. 1a-c). Both sepals and petals have a uniseriate and cuticularized epidermis, and a parenchymatous mesophyll with secretory cavities (Fig. 1c, d). Stomata were observed only in the petals (Fig. 1e). The androecium has, on average, 22 stamens consisting of a filament and a bithecal and tetrasporangiate anther (Fig. 1a, b). The two sporangia of each theca are separated by a septum, consisting of parenchyma cells that degenerate in the late stages 
Fig. 1 Longitudinal and cross sections of 'Fortune' mandarin flower buds at the several developmental stages, indicated by size in millimeters $(\mathrm{mm})$. a Petal, sepal, anther and stigma (3 mm), b filament and anther (5 mm), c sepal, nectary and ovary $(7 \mathrm{~mm}), \mathbf{d}$ epidermis and secretory cavity of the sepals and stigma $(7 \mathrm{~mm})$, e petal stomata $(10 \mathrm{~mm}), \mathbf{f}$ tetrasporangiate anther with tapetum $(3 \mathrm{~mm})$. g Anther with two pollen sacs $(5 \mathrm{~mm})$. h Anther wall $(6 \mathrm{~mm})$. Symbols: an -anther; ct-connective; ed-endothecium; epepidermis; ft—filament; $1 \mathrm{~m}$ middle layer; nd-nectariferous disk; ov—ovary; pe—petal; sc—secretory cavity; se-sepal; sm—stomata; st—stigma; vbvascular bundle; tp—-tapetum
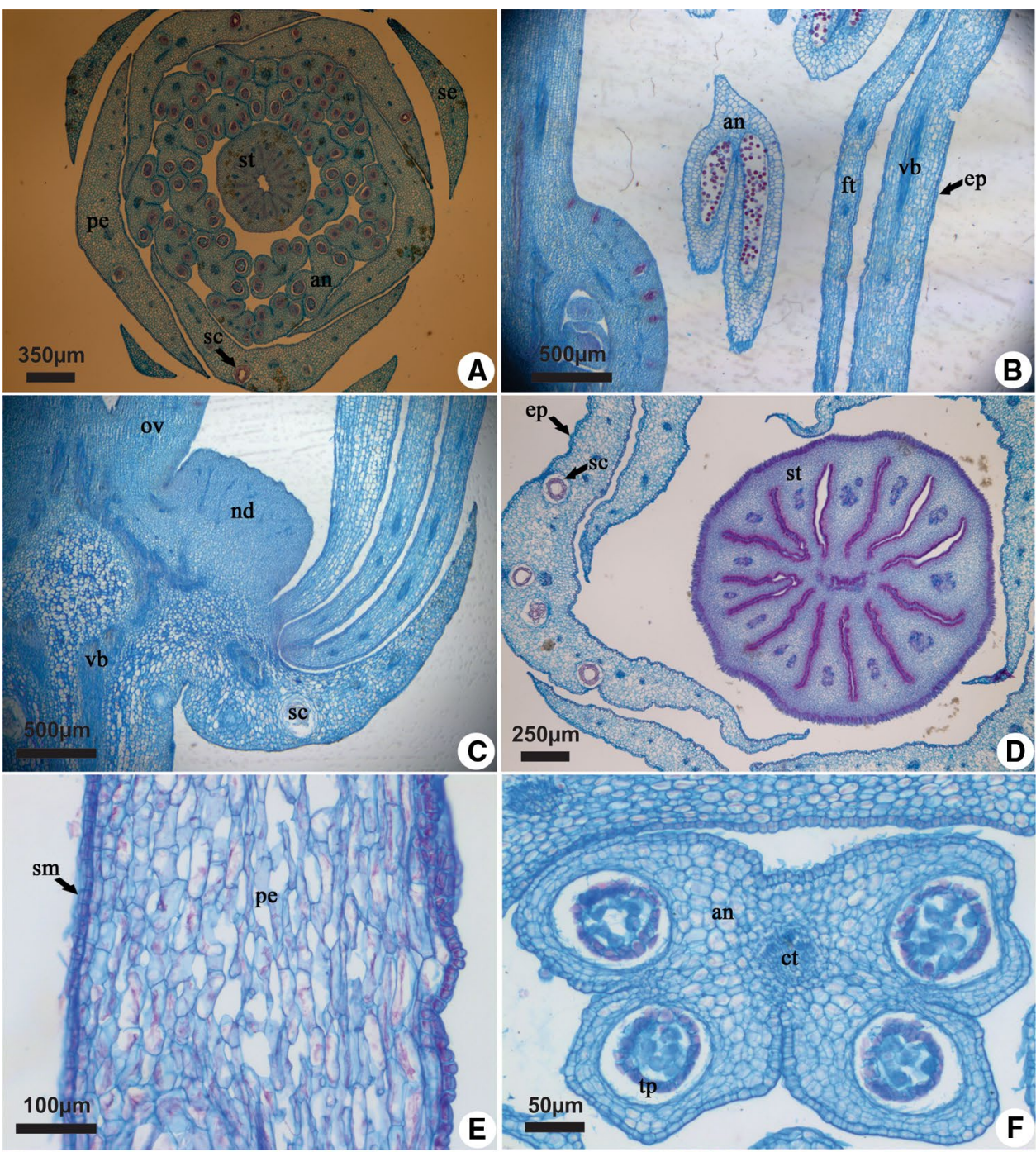

D
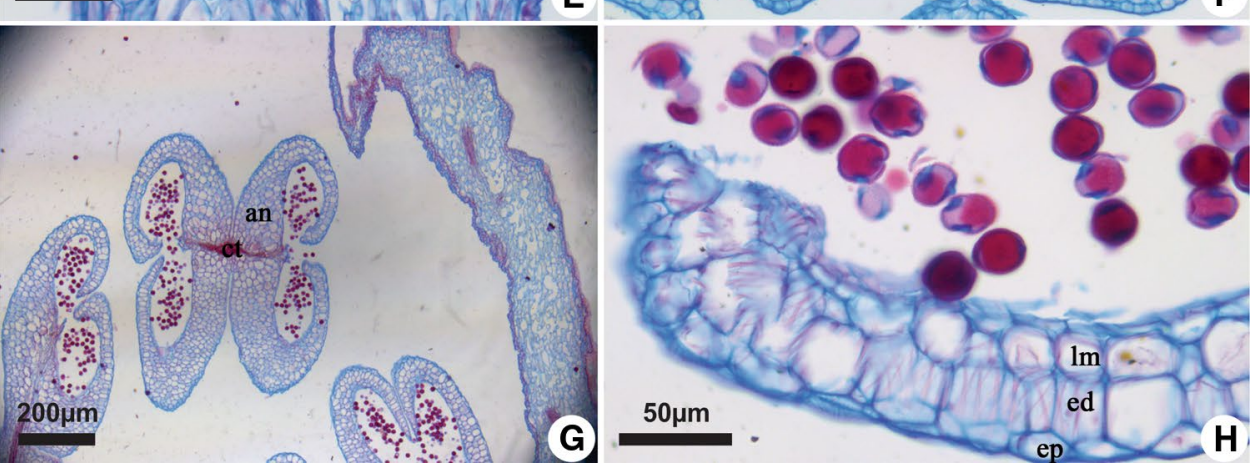

of anther development, with approximate length of $6 \mathrm{~mm}$, forming only two pollen sacs (Fig. 1f, g).

The stamen epidermis is uniseriate and cuticularized, and the mesophyll is parenchymatous and vascularized (Fig. 1b). Four parietal layers were identified in the anthers from bud flowers up to $4 \mathrm{~mm}$ of length: the epidermis, the endothecium, the single middle layer and the tapetum, the last being secretory and binucleate. The tapetum cells already disintegrated in bud flowers longer than $4 \mathrm{~mm}$ (Fig. 1f, h).
The floral bud is hypogenous, presenting an upper ovary and nectariferous disk (Fig. 1c). The ovary presents on average 15 locules, with each locule having one or two ovules with axillary placentation (Fig. 2a, b). The ovary has uniseriate epidermis, stomata, and parenchymatous mesophyll (Fig. 2c). Secretory trichomes were found only in the inner epidermis (Fig. 2d). Each ovule has a nucellus enveloped by both inner and outer integuments, which demarcate a small opening, the micropyle (Fig. 2b, e). 
Fig. 2 Longitudinal and cross sections of 'Fortune' flower buds, indicated by size in millimeters $(\mathrm{mm})$. a Gynoecium $(5 \mathrm{~mm}), \mathbf{b}$, c ovule with inner and outer integuments and nucellus $(8 \mathrm{~mm}), \mathbf{d}$ ovary wall with uniseriate epidermis and stomata $(9 \mathrm{~mm})$, e gland trichomes at the ovary inner epidermis and stomata at the petal epidermis $(9 \mathrm{~mm}), \mathbf{f}$ stigma with papilous epidermal cells and transmission tissue $(10 \mathrm{~mm}), \mathbf{g}$ style with vascular bundle and uniseriate epidermis $(10 \mathrm{~mm})$, $\mathbf{h}$ nectariferous disk with uniseriate epidermis, stomata and crystal $(10 \mathrm{~mm})$. Symbols: cr-crystal; ep-epidermis; sl—filament; ii-inner integument; nd—nectariferous disk; nu-nucellus; ov-ovary; oiouter integument; or-ovule; pc—papilous cells; sc—secretory cavity; sm - stomata; ststigma; tt-transmission tissue; $\mathrm{vb}$ - vascular bundle
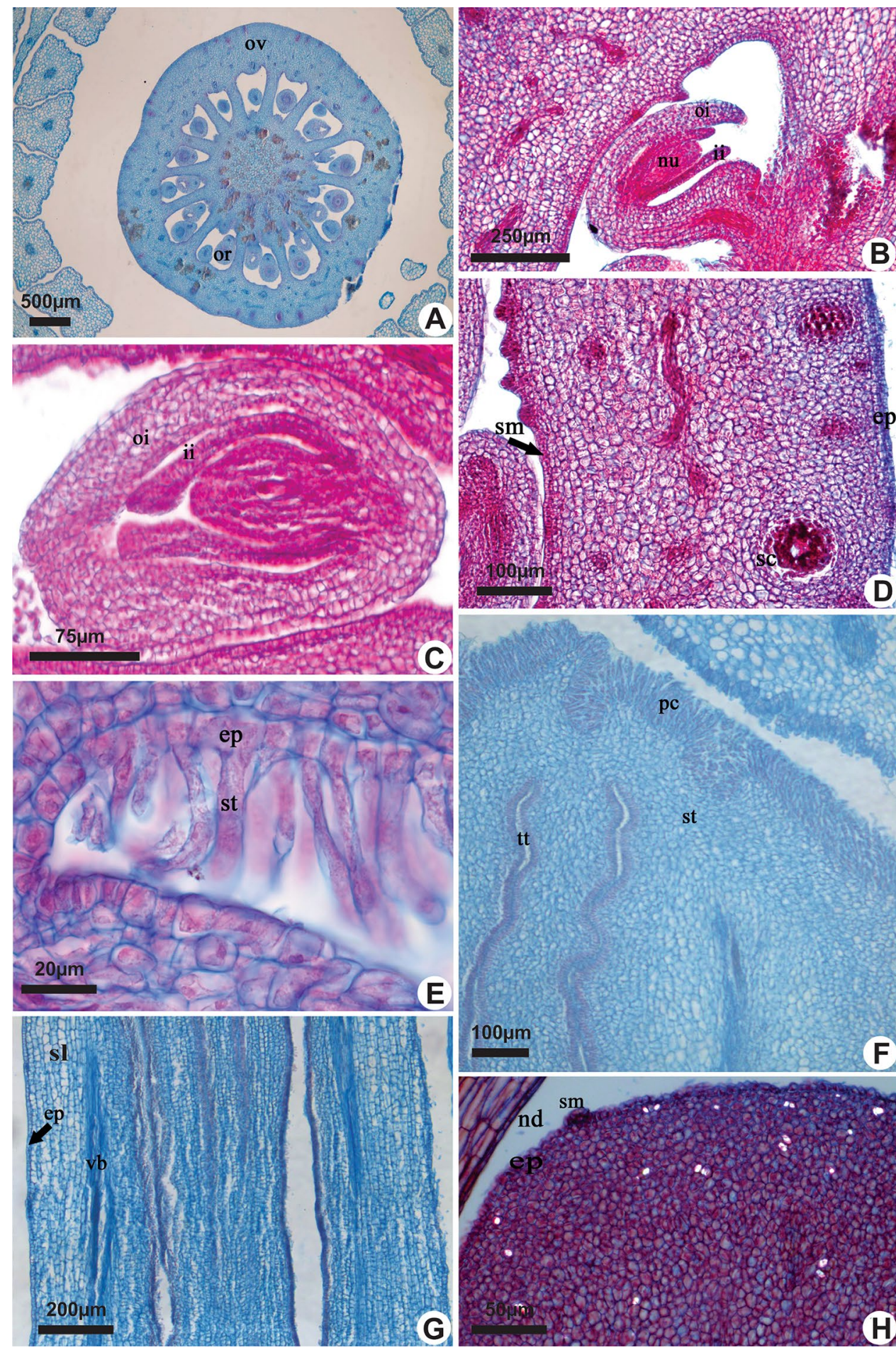
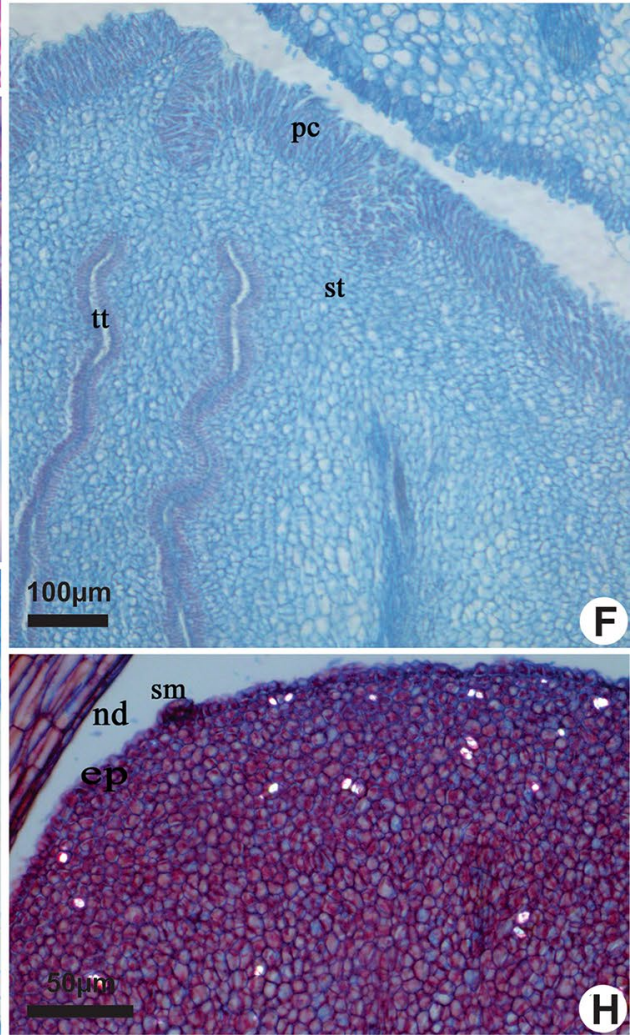

The stigma differs from the style by having small reentrances at the apex and papilous epidermal cells (Fig. 2f). The style has uniseriate epidermis, fundamental parenchyma and is crossed internally by transmission tissue strings (Fig. 2g). The nectariferous disk has uniseriate epidermis with stomata, secretory cavities, parenchyma cells with crystals, and vascular bundles (Figs. 1c, 2h). All of the flower organs possess secretory cavities of several sizes, most of them visible to the naked eye. These cavities are associated with the parenchyma and are larger and more numerous in the ovary and on the outer surface of the sepals and petals (Figs. 1d, 2c).

The sporogenous cells differentiate into microspore mother cells (Fig. 3a). Both callose wall deposition around 
Fig. 3 Longitudinal and cross sections of 'Fortune' flower buds during microsporogenesis and male gametophyte development, indicated by size in millimeters (mm). a, b Anther with microspore mother cell and tapetum $(3 \mathrm{~mm})$, c tetranucleate syncytium, $\mathbf{d}, \mathbf{e}$ microspore tetrads $(4 \mathrm{~mm}), \mathbf{f}$ microspore development (4 mm), g bicellular male gametophyte $(6 \mathrm{~mm}), \mathbf{h}$ male gametophyte with rounded pore and elongated colpus (6 mm). Symbols: $\mathrm{cp}$ - colpus; $\mathrm{mmc}$-microspores mother cell; $\mathrm{mp}$-microspore; $\mathrm{n}$-nucleus; sc-syncytium; tp-tapetum; $\mathrm{v}$-vacuole
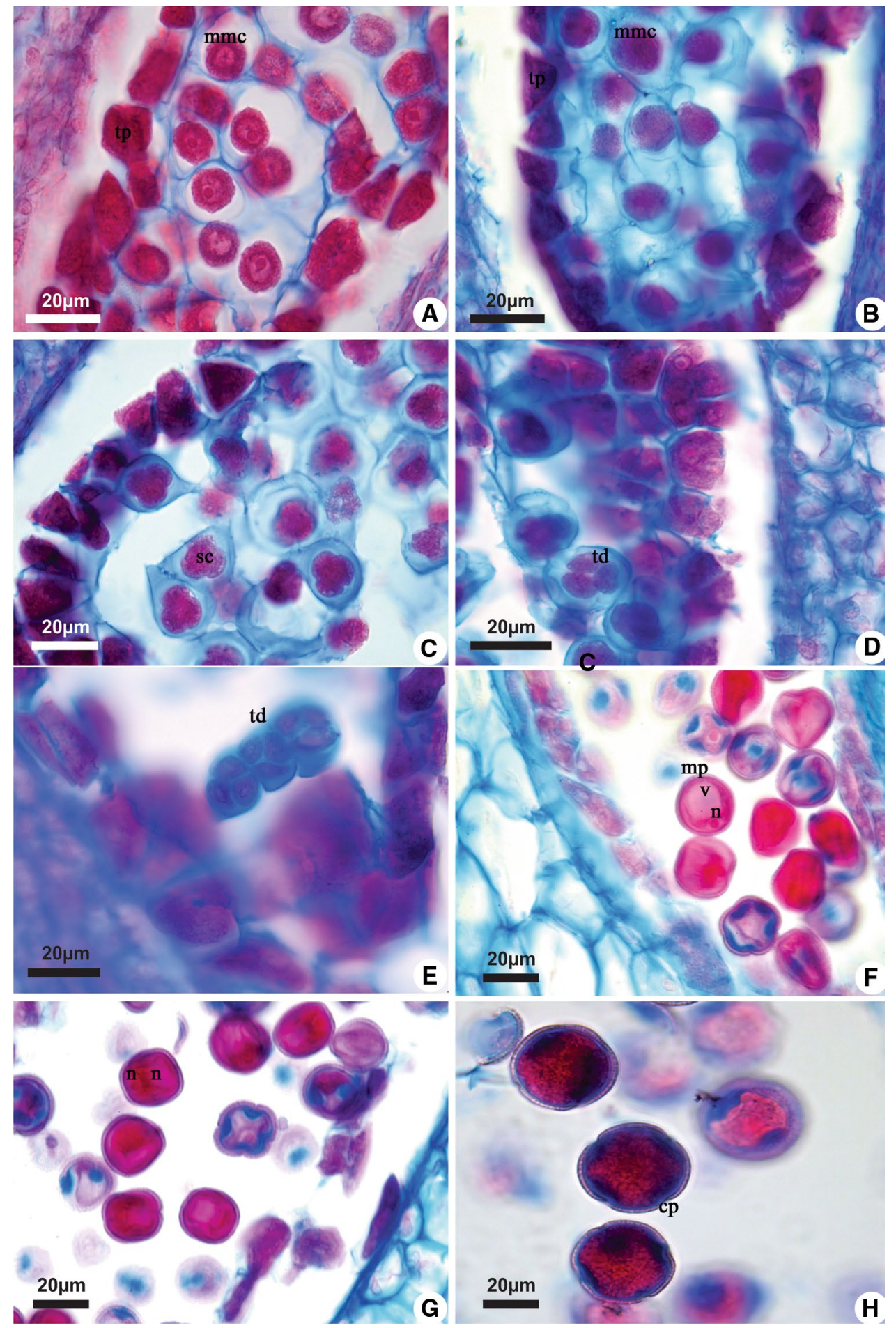

the microspores mother cells and chromatin condensation were observed, marking the onset of the meiotic prophase (Fig. 3a, b). Each microspore mother cell divides by meiosis, giving rise to four cells organized in tetrahedral tetrads (Fig. 3c, d), as a result of simultaneous cytokinesis (Fig. 3d, e). The microspores showed dense protoplast and were uninucleated (Fig. 3f).
The male gametophyte (pollen grain) development occurred mostly in the floral bud, with approximately $6 \mathrm{~mm}$ in length. Pollen formation started with the vacuolization and polarization of the microspore nucleus, which is a characteristic of the beginning of the first mitosis (Fig. 3f, g). The bicellular male gametophyte has a large vegetative cell and a small generative cell (Fig. 3g). The pollen grains have 
four openings of the colporous type, consisting of a circular pore and an elongated colpus (Fig. 3h). The pollen tube emerges from one of these openings during the germination of the pollen grain, which occurs in the stigmatic region of the carpel after pollination.

Microspore development occurred regularly when the floral buds had length of 4-5 mm, and a binucleated gametophyte was formed in the floral buds with length of $6 \mathrm{~mm}$. Approximately $70 \%$ of the angiosperm species release their pollen grains at this binucleate stage. The second mitosis only occurs after pollination of the stigma of the pollen recipient plant before or after the development of the pollen tube. For the remaining 30\%, the cell undergoes a new mitosis, which results in the formation of the two male gamete nuclei. Therefore, the pollen grain constitutes the mature, trinucleated microgametophyte.
During the megasporogenesis, a cell located under the nucellar epidermis became more evident, presenting larger size, denser cytoplasm and more conspicuous nucleus (Fig. 4a). This cell corresponds to the megaspore mother cell, which passes through meiosis to form four cells of linear arrangement (Fig. 4b). Three of these megaspores degenerated and only the chalazal megaspore developed, giving rise to a megagametophyte or embryo sac with eight nuclei (Fig. 4d, f). The formation of the female gametophyte occurred later, in flower buds with approximately $10 \mathrm{~mm}$ in length.
Fig. 4 Longitudinal and cross sections of 'Fortune' flower buds during megasporogenesis and female gametophyte development, indicated by size in millimeters $(\mathrm{mm})$. a Megaspore mother cell $(8 \mathrm{~mm})$, b linear megaspores tetrad $(9 \mathrm{~mm})$, c embryo sac with eight nuclei (10 mm). d, f Embryo sac (10 mm). Symbols: $\rightarrow$-embryo sac nuclei; es-embryo sac; mmc-megaspore mother cell; td-megaspores tetrad

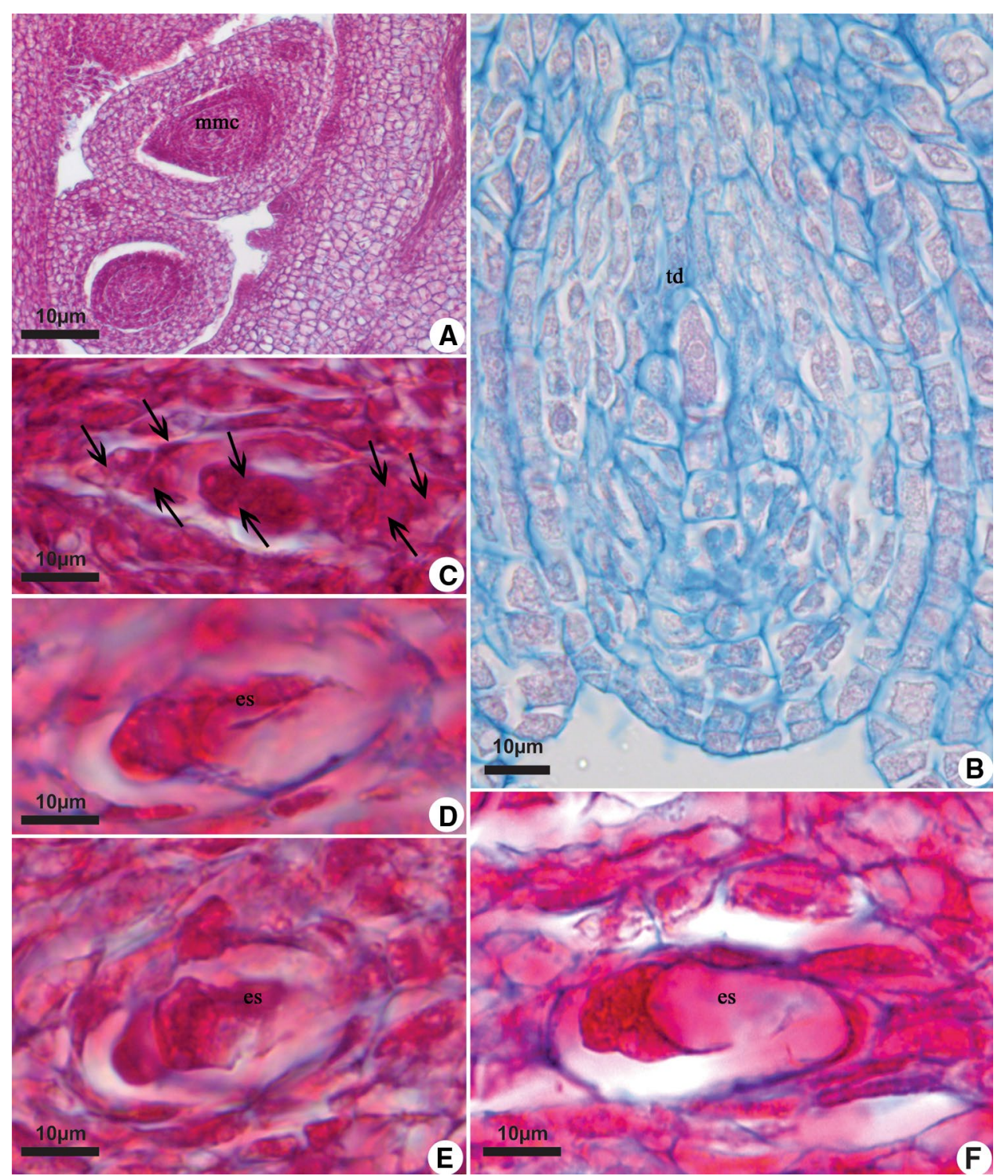




\section{Discussion}

In the crosses between 'Fortune' and 'Dancy' mandarins, the efficiency of formation of triploid hybrids was twice that of the crosses between 'Fortune' and 'Cravo.' The means obtained by the analysis of variance were compared to each other by the Turkey test at 5\% probability, and significant differences between the two treatments were observed for this variable.

The differences were observed concerning the male parents. The 'Cravo' mandarin male parent gave the lowest number of triploid hybrids per seed with 'Fortune' mandarin female parent, whereas the highest number of triploid hybrids per seed was obtained with 'Dancy' mandarin male parent and 'Fortune' female parent. In most of the studied variables, the means obtained in the treatments differed significantly from each other, and treatment 2 was the most promising. Among the mandarins, there are large differences in the number of seeds per fruit, and the pollen of the male gamete used influences the formation of seeds (Bono et al. 2006). The influence of pollen occurs due to the gametophytic self-incompatibility system identified in Citrus (Aleza et al. 2010).

Triploid embryos are mainly found in small seeds (Esen and Soost 1971; Aleza et al. 2010). However, in this study we obtained a higher number of triploid embryos in normal seeds. However, the number of small seeds obtained by Aleza et al. (2010) is much higher than the number of small seeds we obtained, which may have influenced the result, since the greater the number of seeds, the higher the chances of this event occurring. However, the number of normal seeds obtained in the pollinations in this study surpassed that obtained by Aleza et al. (2010).

The triploid plants obtained by the hybridization process performed here indicate the occurrence of failures during the gamete formation. Several authors have reported failures during the separation of the chromosomes in meiosis I and/or meiosis II as a consequence of biotic and abiotic stresses (Mason and Pires 2015), demonstrating the influence of both factors in the process of formation of unreduced gametes. Chen et al. (2008) confirmed that the failures in meiosis I were more frequent than in meiosis II regarding the origin and frequency of unreduced gametes in Citrus sinensis $\times$ Poncirus trifoliata.

Other aspects that must be taken into account are the genetic factors and the contribution of gametes. Several genes related to alterations in meiosis were found in Arabidopsis (d'Erfurth et al. 2008; Storme and Geelen 2011), particularly expressed during megagametogenesis (Chen et al. 2008). According to Aleza et al. (2015), in Citrus clementina (clementine), the triploid embryos are originating from diploid megagametophytes fertilized by normal haploid male gametes. This indicates that the female gametophytes are the ones that contribute the most to obtain triploids in citrus.

In citrus plants, triploid varieties can produce seedless fruits, a characteristic highly desired by producers and consumers. Aleza et al. (2015) obtained a rate of approximately $6 \%$ triploid embryos from the hybridization with a diploid parent. This rate was even higher when the authors only analyzed small seeds, which are strongly associated with the process of obtaining these hybrids. The international markets demand seedless fruits, so this characteristic is one of the most important for citrus, with special emphasis on mandarins (Wang et al. 2016).

Aleza et al. (2010) proposed that triploid production is influenced by the fertilization success of pollen. This success depends on several factors, among them the pollen quality (which can be determined by the male genotype and environmental conditions); the level of compatibility between parent genotypes; and environmental effects on germination of the pollen tube (Geraci et al. 1975).

In this context, the formation of the gametophyte is fundamental for the processes involved in the reproduction of angiosperms, including the orientation of the pollen tube, fertilization and induction of seed development. During fertilization, components of the cytoskeleton present in the female gametophyte direct the sperm cells to the egg cell and to the central cell, and after fertilization the genes in the female gametophyte are expressed to control the development of the embryo and the endosperm (Kimata et al. 2016).

Most studies performed on the floral development of plants have focused on the development of the male gametophyte (Velázquez et al. 2016). It is difficult to analyze the female gametophyte, especially in citrus. Furthermore, the small number of cells that form the seminal rudiment (ovule) tissue, where this process occurs, also makes observations difficult.

The general characteristics the 'Fortune' mandarin observed in the development of the anther and the male gametophyte are quite similar to those observed in most angiosperms (Velázquez et al. 2016). Within the anthers, the sporogenic cells differentiated and performed meiosis to produce microspores, which passed through mitosis and formed male gametophytes or pollen grains. The cells of the anther wall surrounding the sporogenic tissue are related to the maturation, protection and release of pollen. Thus, the development of the gametophyte can be said to involve a series of crucial steps, including cell division and differentiation.

This article presents the first histological description of male and female organs of mandarins plants. These characteristics are fundamental for the development of breeding programs aimed at obtaining triploid hybrids. Another 
important characteristic was the effect of the male parent 'Dancy' to obtain these hybrids more frequently.

Analysis of floral structures allows verifying the occurrence of abnormalities during the development of male and female gametophytes and gametes. In addition, it allows identifying if there is more than one embryo sac, which indicates the occurrence of more than one embryo. However, we did not find any abnormality that could be associated with the formation of unreduced gametes and triploid embryos. Other analyses, such as those related to the size of the pollen grains, are indicative, but do not show this feature with certainty.

Acknowledgements We thank Liziane Marques dos Santos, Maria Aparecida dos Santos de Jesus and Nayara de Almeida Santos for their kind technical assistance; the Electron Microscopy Center of Santa Cruz State University (UESC), Ilhéus, BA, for providing the facilities for microscopic analyses; the National Council for Scientific and Technological Development (CNPq) for the financial support (Grants 301356/2012-2 and 472733/2013-3); and the Coordenação de Aperfeiçoamento de Pessoal de Nível Superior (CAPES) for the scholarship to the first author.

Authors contribution SNC was involved in conception and design of experiment, acquisition of data, analysis and interpretation of data, and writing and revision of the manuscript. PAC acquired, analyzed and interpreted the data and wrote and revised the manuscript. LAHA was involved in conception and design of the experiment. FMM analyzed and interpreted the data and wrote and revised the manuscript. WSSF was involved in conception and design of the experiment. MACF was involved in conception and design of the experiment. ASG was involved in conception and design of the experiment, writing and revision of the manuscript.

\section{References}

Abouzari A, Mahdi MN (2016) The investigation of Citrus fruit quality. Popular characteristic and breeding. Acta Univ Agric Silvic Mendel Brun 64:725-740. https://doi.org/10.11118/actaun2016 64030725

Aleza P, Juárez J, Ollitrault P, Navarro L (2009) Production of tetraploid plants of non apomictic Citrus genotypes. Plant Cell Rep 28:1837-1846. https://doi.org/10.1007/s00299-009-0783-2

Aleza P, Juárez J, Cuenca J, Ollitrault P, Navarro L (2010) Recovery of Citrus triploid hybrids by embryo rescue and flow cytometry from $2 x \times 2 x$ sexual hybridisation and its application to extensive breeding programs. Plant Cell Rep 29:1023-1103. https://doi. org/10.1007/s00299-010-0888-7

Aleza P, Cuenca J, Hernández M, Juárez J, Navarro L, Ollitrault P (2015) Genetic mapping of centromeres in the nine Citrus clementina chromosomes using half-tetrad analysis and recombination patterns in unreduced and haploid gametes. BMC Plant Biol 15:80-93. https://doi.org/10.1186/s12870-015-0464-y

Bono R, Soler J, Buj A, Villalba D,Salvia J, Bellver R, Mares M, Méndez JV, Gavilá L (2006) El problema de la presencia de semillas en los frutos cítricos. Conselleria de Agricultura Pesca y Alimentación, Ficha Técnica serie citricultura, 5

Chen C, Lyon MT, O'Malley D, Federici C, Gmitter J, Gosser JW, Chaparro JX, Rosse ML, Gmitter FR Jr (2008) Origen and frequency of $2 \mathrm{n}$ gametes in Citrus sinensis $\times$ Poncirius trifoliata and their reciprocal crosses. Plant Sci 174:1-8. https://doi. org/10.1016/j.tig.2007.08.005

Cruz CD (2006) Programa Genes: Biometria, 1st edn. Editora UFV, Viçosa (MG)

D'Erfurth I, Jolivet S, Froger N, Catrice O, Novatchkova M, Simon M, Jenczewski E, Mercier R (2008) Mutations in AtPS1 (Arabidopsis thaliana parallel spindle 1) lead to the production of diploid pollen grains. PLoS Genet 4:e1000274. https://doi. org/10.1371/journal.pgen.1000274

Dolezel J, Greilhuber J, Suda J (2007) Estimation of nuclear DNA content in plants using flow cytometry. Nat Protoc 2:2233-2244. https://doi.org/10.1038/nprot.2007.310

Esen A, Soost RK (1971) Unexpected triploids in citrus: their origin, identification and possible use. J Hered 62:329-333. https://doi. org/10.1093/oxfordjournals.jhered.a108186

Food and Agriculture Organization of the United Nations. Food and agriculture (2017). FAO http://www.fao.org/faostat/en/\#home. Acessed 27 July 2017

Gerlach G (1969) Botanische mikrotechnik: eine einfuhrung, 3rd edn. Georg Thieme Verlag, Stuttgart

Geraci G, Esen A, Soost RK (1975) Triploid progenies from 2x x 2x crosses of Citrus cultivars. J Hered 66:177-178. https://doi. org/10.1093/oxfordjournals.jhered.a108607

Guerra M (2009) Chromosomal variability and the origin of Citrus species. In: Mahone CL, Springer DA (eds) Genetic diversity. Nova Science Publishers Inc, New York, pp 51-68

Hodgson RW (1967) Horticultural varieties of Citrus. In: Reuther W, Webber HJ, Batchelor LD (eds) The Citrus industry. University of California Press, California, pp 432-459

Iglesias DJ, Cercós M, Colmenero-Flores JM, Naranjo Ríos G, Carrera E, Ruiz-Rivero O, Lliso-Morillon LR, Tadeo FR, Talon M (2007) Physiology of Citrus fruiting. Braz J Plant Physiol 19:333-362. https://doi.org/10.1590/S1677-042020070004000 06

Johansen DA (1940) Plant microtechnique, 1st edn. McGraw-Hill Book Company, New York

Kimata Y, Higaki T, Kawashima T, Kurihara D, Sato Y, Yamada T, Seiichiro H, Frederic B, Tetsuya H, Ueda M (2016) Cytoskeleton dynamics control the first asymmetric cell division in Arabidopsis zygote. Proc Natl Acad Sci USA. https://doi.org/10.1073/ pnas. 1613979113

Lloyd G, Mccown B (1981) Commercially feasible micropropagation of mountain laurel, Kalmia latifolia, by use of shoot tip culture. Int Plant Propag Soc 30:421-427

Mason AS, Pires JC (2015) Unreduced gametes: meiotic mishap or evolutionary mechanism? Trends Genet 31:5-10. https://doi. org/10.1016/j.pmr.2014.09.011

Ollitrault P, Dambier D, Luro F, Froelicher Y (2008) Ploidy manipulation for breeding seedless triploid Citrus. Plant Breed Rev 30:323-354. https://doi.org/10.1002/9780470380130.ch7

Otto SP (2007) The evolutionary consequences of polyploidy. Cell 131:452-462. https://doi.org/10.1016/j.cell.2007.10.022

Pécrix Y, Rallo G, Folzer H, Cigna M, Gudin S, Manuel Le Bris M (2011) Polyploidization mechanisms: temperature environment can induce diploid gamete formation in Rosa sp. J Exp Bot 62:3587-3597. https://doi.org/10.1093/jxb/ers387

Soost RK, Cameron JW (1975) Advances in fruit breeding. In: Jannick J, Moore JN (eds) Citrus. Purdue University Press, West Lafayette, pp 507-540

Storme N, Geelen D (2011) The Arabidopsis mutant jason produces unreduced first division restitution male gametes through a parallel/fused spindle mechanism in meiosis II. Plant Physiol 155:1403-1415. https://doi.org/10.1104/pp.110.170415

Storme N, Geelen D (2013) Sexual polyploidization in plantscytological mechanisms and molecular regulation. New Phytol 198:670-684. https://doi.org/10.1111/nph.12184 
Van Genuchten MT (1980) A closed form equation for predicting the hydraulic conductivity of unsaturated soils. Soil Sci Soc Am J 44:892-898. https://doi.org/10.2136/sssaj1980.036159950044000 $50002 x$

Velázquez TLC, Hernández ARA, Figueroa-Castro DM, Villanueva AC (2016) Anatomy of the reproductive structures of Stenanona flagelliflora (Annonaceae). Brazi J Bot 39:679-687. https://doi. org/10.1007/s40415-016-0252-4

Wang X, Cheng ZM, Zhi S, Xu F (2016) Breeding triploid plants: a review. Czech J Genet Plant Breed 52:41-54. https://doi. org/10.17221/151/2015-CJGPB
Publisher's Note Springer Nature remains neutral with regard to jurisdictional claims in published maps and institutional affiliations. 